SC-TM-66-393

Technical Memorandum

September 1966

\title{
A SIX-DEGREE-OF-FREEDOM INVESTIGATION OF THE MOTION OF TWO SNAP FUEL CAPSULE CONFIGURATIONS RE-ENTERING THE ATMOSPHERE WITH VARIOUS INITIAL CONDITIONS
}

D. H. Johnson, 9321

This is a SANDIA CORPORATION working paper and is intended primarily for internal distribution; the ideas expressed herein do not necessarily reflent the opinion of the Corporation.

RELES SED FOR ANNOUNCEMENT

IN RUCLEAR SCIENCE ABSTRACIS

\section{SANDIA CORPORATION}




\section{DISCLAIMER}

This report was prepared as an account of work sponsored by an agency of the United States Government. Neither the United States Government nor any agency Thereof, nor any of their employees, makes any warranty, express or implied, or assumes any legal liability or responsibility for the accuracy, completeness, or usefulness of any information, apparatus, product, or process disclosed, or represents that its use would not infringe privately owned rights. Reference herein to any specific commercial product, process, or service by trade name, trademark, manufacturer, or otherwise does not necessarily constitute or imply its endorsement, recommendation, or favoring by the United States Government or any agency thereof. The views and opinions of authors expressed herein do not necessarily state or reflect those of the United States Government or any agency thereof. 


\section{DISCLAIMER}

Portions of this document may be illegible in electronic image products. Images are produced from the best available original document. 


\title{
A SIX-DEGREE-OF-FREEDOM INVESTIGATION OF THE MOTION OF TWO SNAP FUEL CAPSULE CONFIGURATIONS RE-ENTERING THE ATMOSPHERE WITH VARIOUS INITIAL CONDITIONS
}

D. H. Johnson, 9321

Sandia Laboratory, Albuquerque

September 1966

\begin{abstract}
The aerodynamic characteristics of two SNAP fuel capsule configurations were determined by using Newtonian theory. For one of these configurations (a cylindrical body with hemispherical end caps), several six-degree-of-freedom trajectories were run using the NASA Six-Degree-of-Freedom Program on the IBM 790 machine in order to study its motion as it re-entered the atmosphere from orbit around the earth. Particular attention was paid to the tumbling motion of the capsule. Also, a literature search was made to determine what has been done in the way of measuring the aerodynamic characteristics of right circular cylinders. A summary of the available experimental data is given, and a comprehensive bibliography is included in the report.
\end{abstract}

\section{LEGAL NOTICE}

States, nor the Commission, nor any person acting on befolf of thed work Neither the United A. Makes ant warranty or representation, expressed or of the Commiasion of any informatios, or usefuines of the informatton contatned in with respect to the accuof any information, apparatus, method, or process disclased in this report, or that the use privately owned rights; or
B. Assumes any liabilities with or process disclosed in this report may not infringe se of any informathy liabill

As used in the above "per, methecl, or process disclobed dandges resultung frum the ployee or contractor of the "person acting on behalf of the com this report.

such employee or of the Commission, or employee of such conssion" meludes any emdisseminates, or provides act the Cummission, or employ ec of suctor, to the extem that with the Commission, or his employ, any information pursuant to his emploractor prepdres, 
DISIRIBLTI( IN

A. Y. Pope, 9300

1. Г. Tlake, Jr., 9310

H. L. Hanser, 9311

५. I. Jeffers, 9312

†. VcAlees, Jr., 9314

H. R. Spahr, 9314

J. D. Appel, 9319

R. C. Naydew, 9320

H. R. Vaughn, 9321

D. H. Johnson, 9321 (2)

11. H. Currv, 9322

t. C. Rightley, 9323

U. R. Barton, 9324

I. h. Cole, 9325

k. J. Touryan, 9326

V. N. Caudle, 9327

A. J. Clark, 9330

i. W. McKiernan, 9331

W. F. Carstens, 3410

R. S. Gillespie, 3413 (4)

B. R. Allen, 3421

U. Scott, $3428-1$

Г. A. Paxton, 8232

C. H. Sproul, $3415-3$ (5)

ssued bi Sandia Corporation,

a prime contractor to the

United stiten Itomis Energy Commisusion

\section{LE G A L NOT I C E}

Thi rport was prepared as an account of Government sponsored xork. $\checkmark$ ither the nited tatec, nor the (ommission, nor anv person artang on behalf of the commissio

1. Vakes any xarranty or representation, exprecied or implied, with re pect to the accuracy, comploteress, or ucetulness of the information contained 11. this report, or that the use of any information, apparatus, method, or procese disclosed in this report may not infringe privately owned rights or

1) issumes any liabilities with respect to the use of, or for damages resuling from the use of any information, apparatus, method, or process disclosed in this report.

is lised in the above, "person acting on behalf of the Commission" includes ar emplave or contractor of the Commission, or emplovee of such contractor, to the extent that such emrloste or contractor of the Commission, or employee of ich contractor preparea, disseminates, or provides access to, any information pirsuant to his employment or contract with the commission, or his employment it ith such contractor. 


\author{
LIST OF SYMBOLS \\ Introduction \\ Statement of the Problem \\ Theoretical Analysis \\ Analysis of Configuration 1 - The Hemispherical Caps \\ Analysis of Configuration 1 - The Cylindrical Body \\ Analys is of Configuration 1 - Damping in Pitch \\ Analysis of Configuration 1 - The Total Configuration \\ Analysis of Configuration 2
}

Survey of Available Experimental Data

Conclusions

LIST OF REFERENCES

\section{LIST OF ILLUSTRATIONS}

\section{Figure}

1. Dimensions of the Two SNAP Fuel Rod Configurations

2. Euler Angle of Attack versus Time for Configuration 1, Case 1

3. Euler Angle of Attack versus Time for Configuration 1, Case 2

4. Euler Angle of Attack versus Time for Configuration 1, Case 3

5. Aerodynamic Coefficients of Configurations 1 and 2 versus Angle of Attack

6. Aerodynamic Flight Regimes

7. Coordinate System Used to Analyze the Hemispherical End Caps of Configuration 1

8. Coordinate System Used to Analyze the Cylindrical Body of Configurations 1 and 2

9. Geometrical Relations Needed to Determine the Damping in Pitch Coefficient

10. Experimentally Determined Normal Force Coefficient versus Mach Number for Right Circular Cylinders at Angles of Attack of 90 Degrees

11. Experimentally Determined Axial Force Coefficient versus Mach Number for Right Circular Cylinders at Angles of Attack of 0 Degrees

12. Experimentally Determined Normal Force Coefficient Slope versus Mach Number for Right Circular Cylinders at Angles of Attack of 0 Degrees

13. Experimentally Determined Center of Pressure $\left(x_{c p} / L\right)$ Measured from the Base of a Right Circular Cylinder at Zero Angle of Attack versus Mach Number

14. Experimentally Determined Axial Force Coefficient versus Angle of Attack for a Right Circular Cylinder 


\section{LIST OF SYMBOLS}

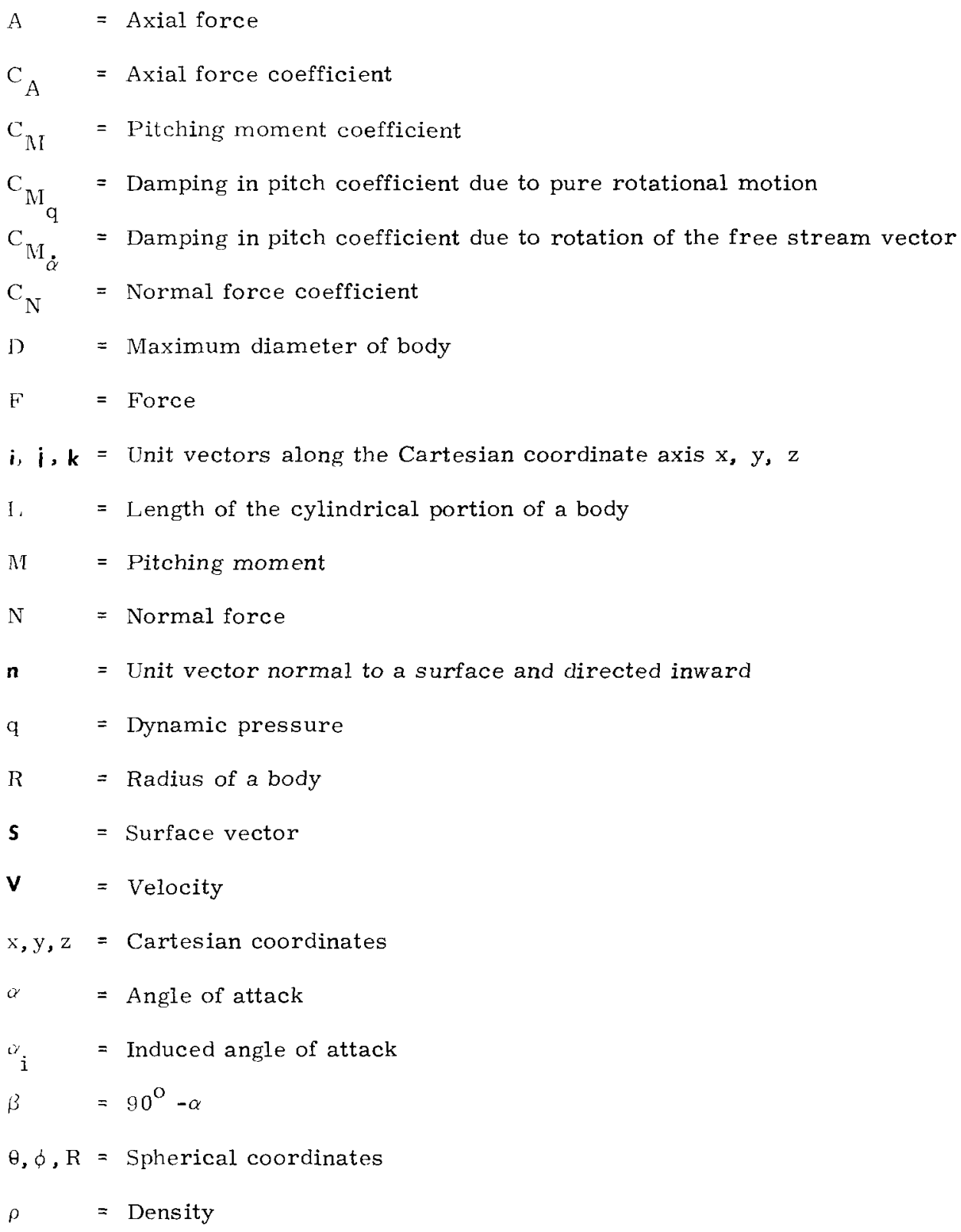

$=$ Density 


\section{A SIX-DEGREE-OF-FREEDOM INVESTIGATION OF THE MOTION OF TWO SNAP FUEL CAPSULE CONFIGURATIONS RE-ENTERING THE ATMOSPHERE WITH VARIOUS INITIAL CONDITIONS}

Introduction

The aerodynamic characteristics of two SNAP fuel capsule configurations were determined by using Newtonian theory. For one of these configurations (a cylindrical body with hemispherical end caps), several six-degree-of-freedom trajectories were run using the NASA Six-Degree-of-Freedom Program on the IBM 790 machine in order to study its motion as it re-entered the atmosphere from orbit around the earth. Particular attention was paid to the tumbling motion of the capsule. Also, a literature search was made to determine what has been done in the way of measuring the aerodynamic characteristics of right circular cylinders. A summary of the available experimental data is given, and a comprehensive bibliography is included in the report.

This study was conducted by Division 9321 at the request of Division 9312 .

\section{Statement of the Problem}

Two fuel capsules with the following physical characteristics were to be studied:

\section{Configuration 1}

Shape: Right circular cylinder with hemispherical end caps

Center of Gravity: On center line at midpoint of capsule

Weight: 1.3 pounds

Pitch and Yaw Moments of Inertia: $3.128 \mathrm{lb}-$ in $^{2}$

Roll Moment of Inertia: $0.176 \mathrm{lb}-\mathrm{in}^{2}$.

\section{Configuration 2}

Shape: Right circular cylinder with indented end caps

Center of Gravity:

Case 1: On center line at midpoint of capsule length

Case 2: 0.061 in off-center line at midpoint of capsule length (center of gravity to be in tumble plane)

Case 3: On center line 1.4035 in from midpoint of capsule length

Weight: 1.3 pounds.

Configurations 1 and 2 are shown in Figure 1. 


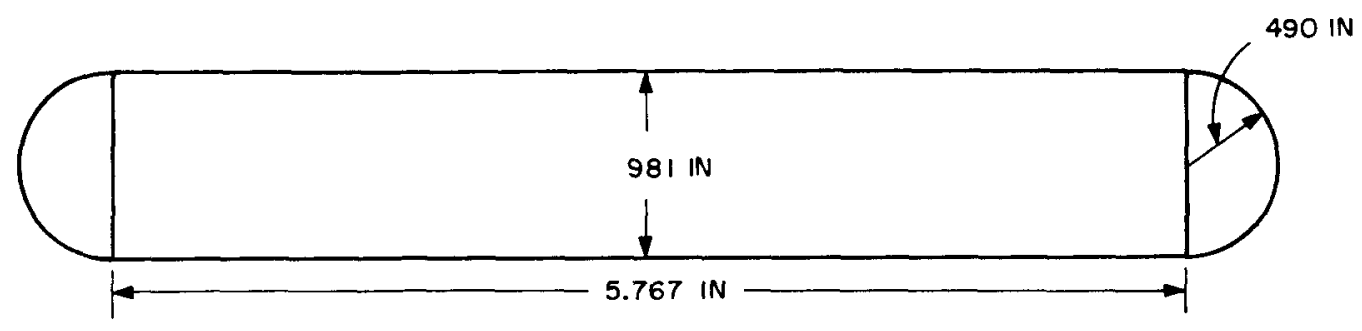

Configuration 1

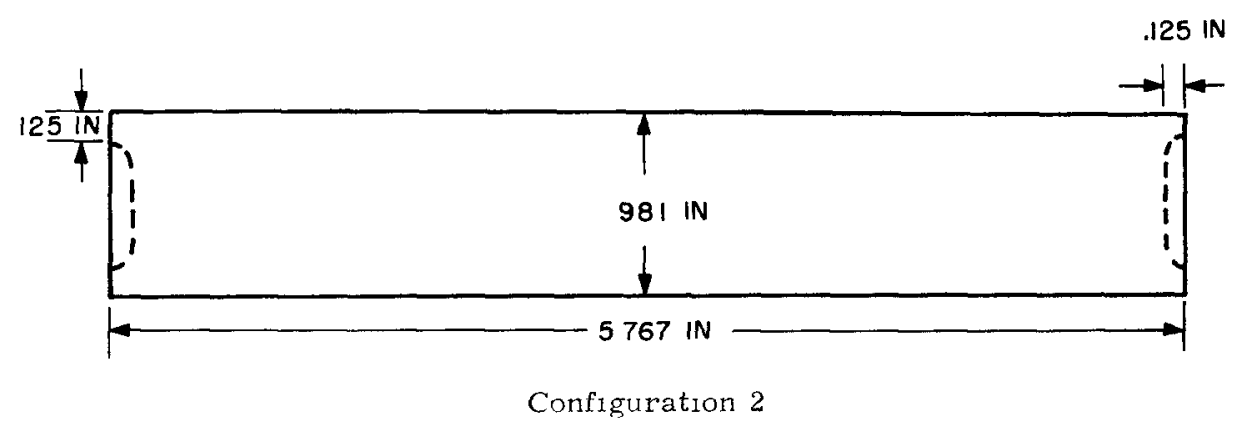

Figure 1. Dimensions of the Two SNAP Fuel Rod Configurations

The aerodynamic coefficients of Configuration 1 were determined using the best theory and all avallable experimental data to compute three six-degree-of-freedom trajectories with the following initial conditions.

General Initial Conditions

Time 0 sec

Hezght $265,595 \mathrm{ft}$

Latitudes $36.285 \mathrm{deg}$

Longatude $179.3 \mathrm{deg}$

Velocity $25,161 \mathrm{ft} / \mathrm{sec}$

Euler Angles $(\psi, \phi, \theta) \quad 92.78 \mathrm{deg}, 0 \mathrm{deg},-0.788 \mathrm{deg}$.

Trajectory 1

Orientation Capsule axis aligned with flight path

Yaw Rate $0 \mathrm{deg} / \mathrm{sec}$

Pitch Rate: $4 \mathrm{deg} / \mathrm{sec}$

Roll Rate $0 \mathrm{deg} / \mathrm{sec}$ 


\section{Trajectory 2}

Orientation Capsule axis aligned with flight path

Yaw Rate $0 \mathrm{deg} / \mathrm{sec}$

Pitch Rate $115 \mathrm{deg} / \mathrm{sec}$

Roll Rate $0 \mathrm{deg} / \mathrm{sec}$.

Trajectory 3

Orientation

Yaw Rate 0 deg/sec

Pitch Rate $20 \mathrm{deg} / \mathrm{sec}$

Roll Rate $0 \mathrm{deg} / \mathrm{sec}$.

The aerodynamic coefficients of Configuration 2 were determined using the most expedient method and compared with those of Configuration 1. No trajectories were computed for Configuration 2.

\section{Theoretical Analysis}

The requested six-degree-of-freedom trajectories have been run, and in Figures 2 , 3 , and 4 , the Euler angle of pitch is plotted versus time for each of the three sets of initial conditions. Also, the aerodynamic coefficients for Configuration 2 have been computed and are compared with those of Configuration 1 in Figure 5 . The rest of this section will be devoted to outlining the analytical methods used to determine the aerodynamic coefficients of these two configurations.

First, the flight regimes through which the capsules pass must be determined. Figure 6 shows the combinations of Mach number, Reynolds number, and Knudsen number which fall within the varıous regimes of free molecular, intermediate, slip, and continuum flow. ${ }^{1}$ The given initial conditions for Configuration 1 all fall within the slip flow regime. The best theory avallable for this region, short of exact numerical solutions, 1s Newtonian theory. ${ }^{2}$ Thus Configuration 1 was analyzed using Newtonian theory. The hemispherical caps were considered separately from the cylindrical body.

Analysis of Configuration 1 - The Hemispherical Caps

Figure $7 \mathrm{a}$ shows the spherical coordinate system used to analyze the caps, and Figure $7 \mathrm{~b}$ shows the relation of this system to the cylindrical body and the rectangular coordinate systems along which all aerodynamic forces were resolved. The unt vector normal to the surface of a cap and directed inward is

$$
\mathbf{n}=-\sin \phi \cos \theta \mathbf{i}-\sin \phi \sin \theta \mathbf{i}-\cos \phi \mathbf{k} \text {. }
$$

The velocity vector of the flow relative to the cap is

$$
\mathbf{v}=\mathbf{v} \mathbf{i}
$$

Thus, the force caused by an infunitesimal stream-tube of air hitting a cap and losing its normal component of momentum is

$$
\begin{aligned}
& d \mathbf{F}=-\rho(\mathbf{V} \cdot \mathbf{n})^{2} d \mathbf{S} \\
& d \mathbf{F}=-\rho V^{2} R^{2} \sin ^{2} \phi \cos ^{2} \theta[\sin \phi \cos \theta \mathbf{i}+\sin \phi \sin \theta \mathbf{j}+\cos \phi \mathbf{k}] d \phi d \theta .
\end{aligned}
$$




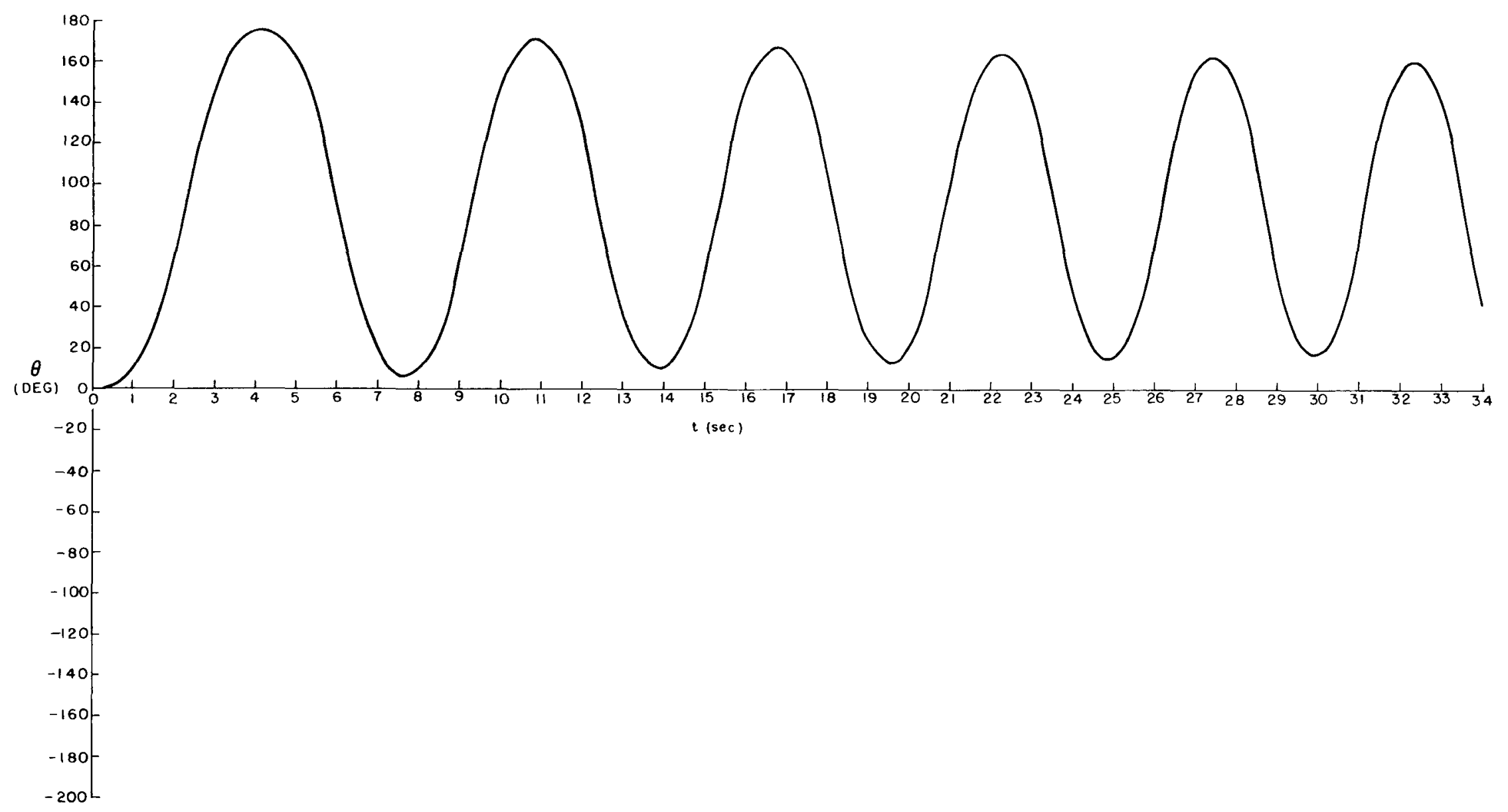

Figure 2. Euler Angle of Pitch versus Time for Configuration 1, Case 1 


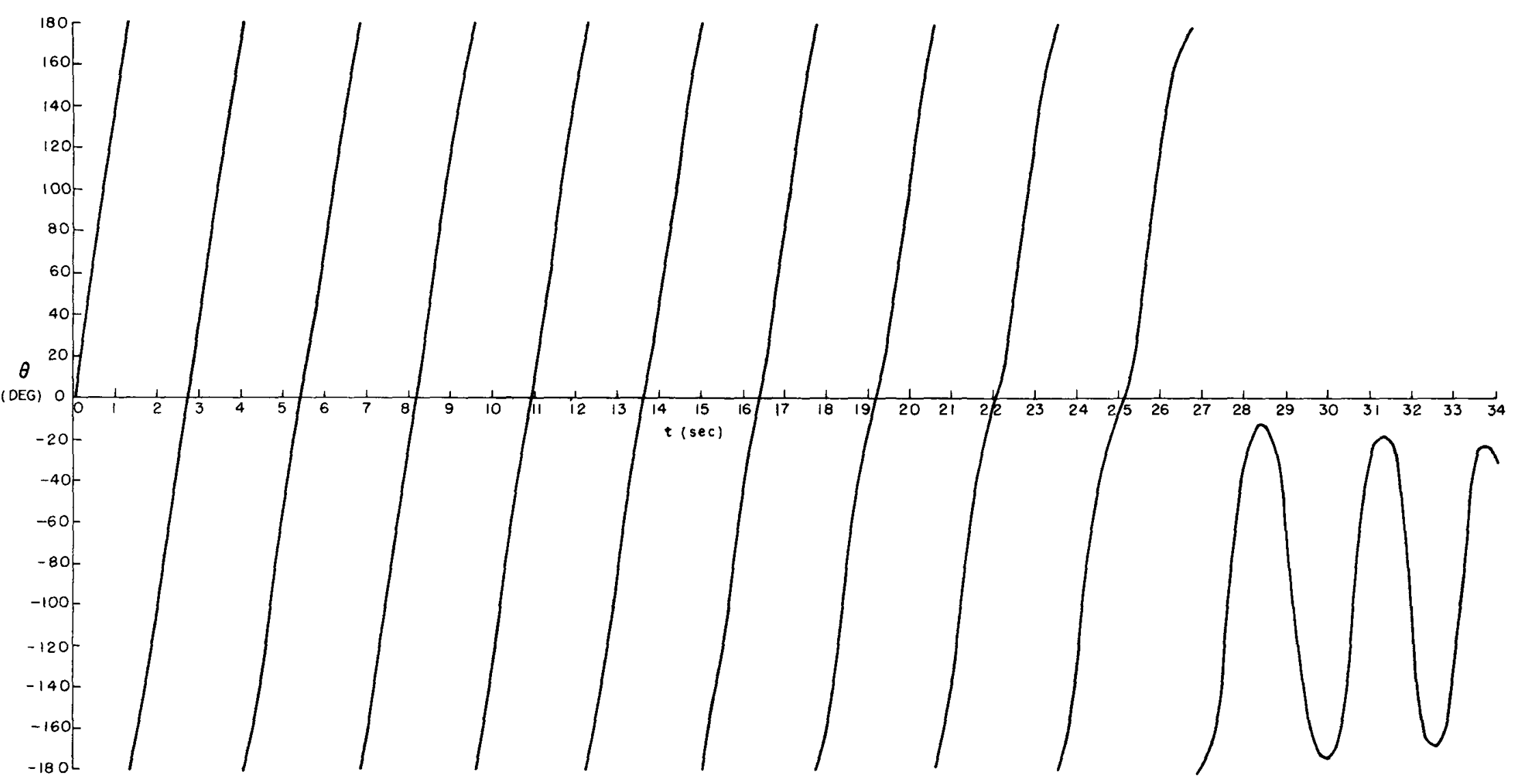

Figure 3. Euler Angle of Pitch versus Time for Configuration 1, Case 2 


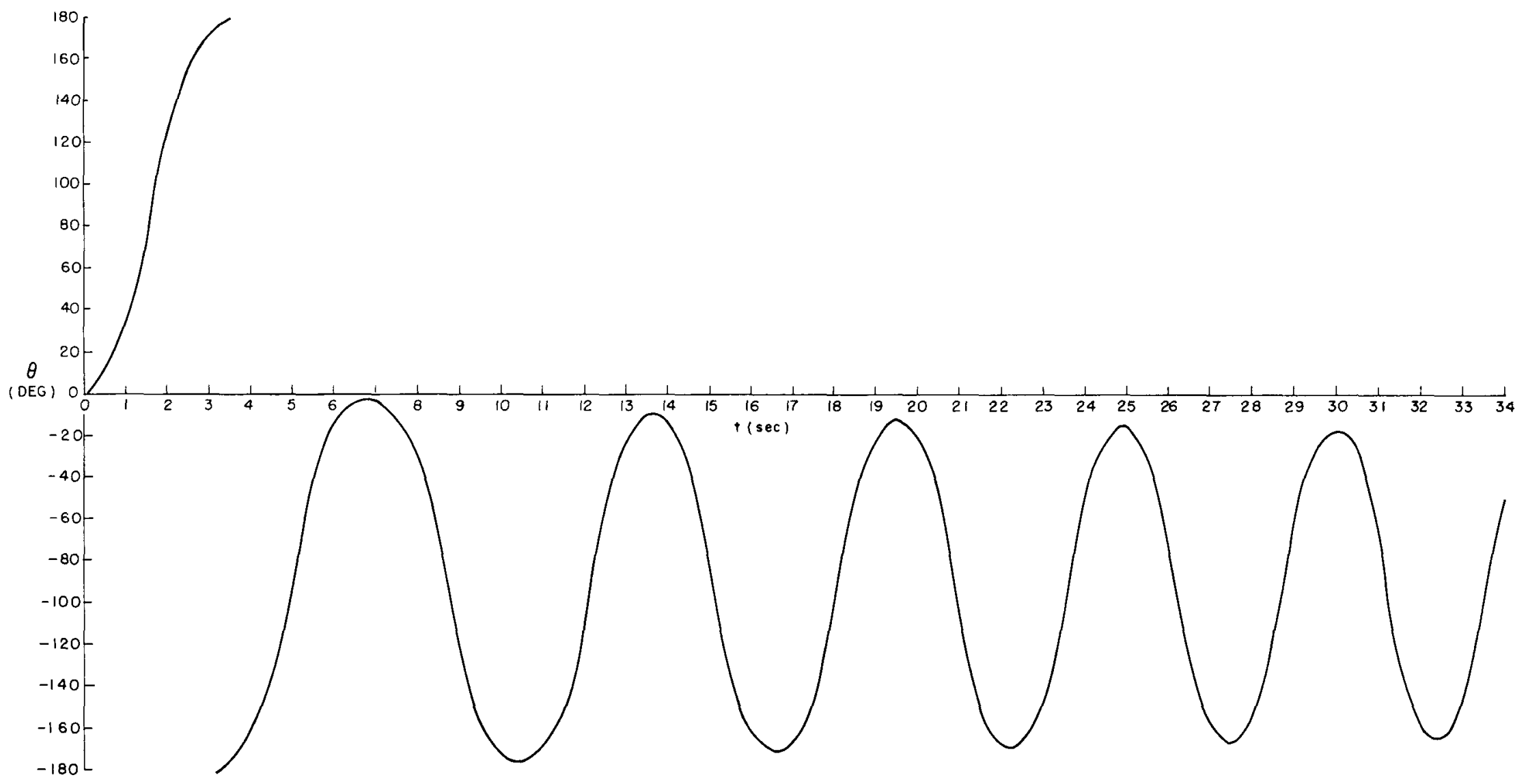

Figure 4. Euler Angle of Pitch versus Time for Configuration 1, Case 3 


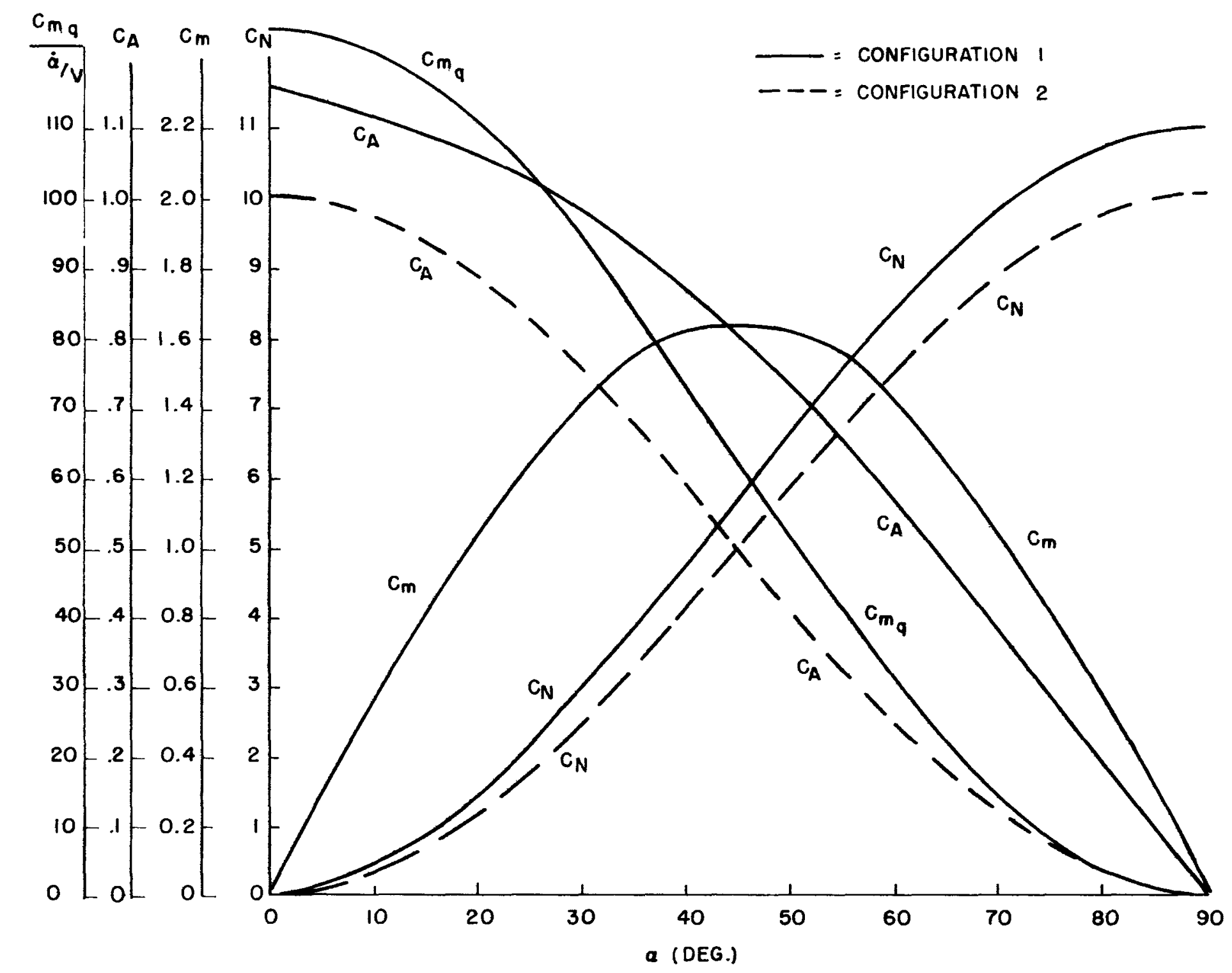

Figure 5. Aerodynamic Coefficients of Configurations 1 and 2 versus Angle of Attack 


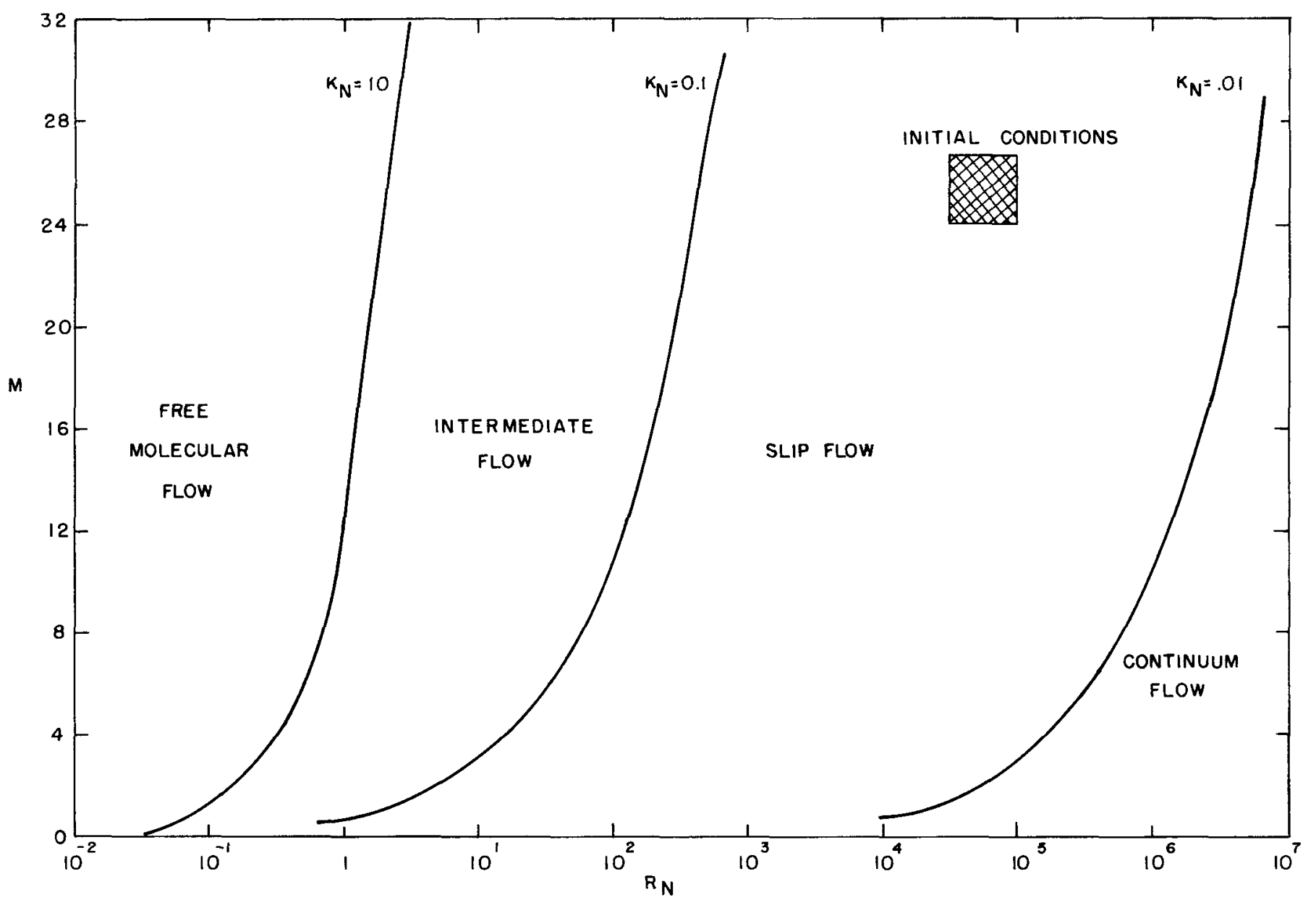

Figure 6. Aerodynamic Flight Regimes 


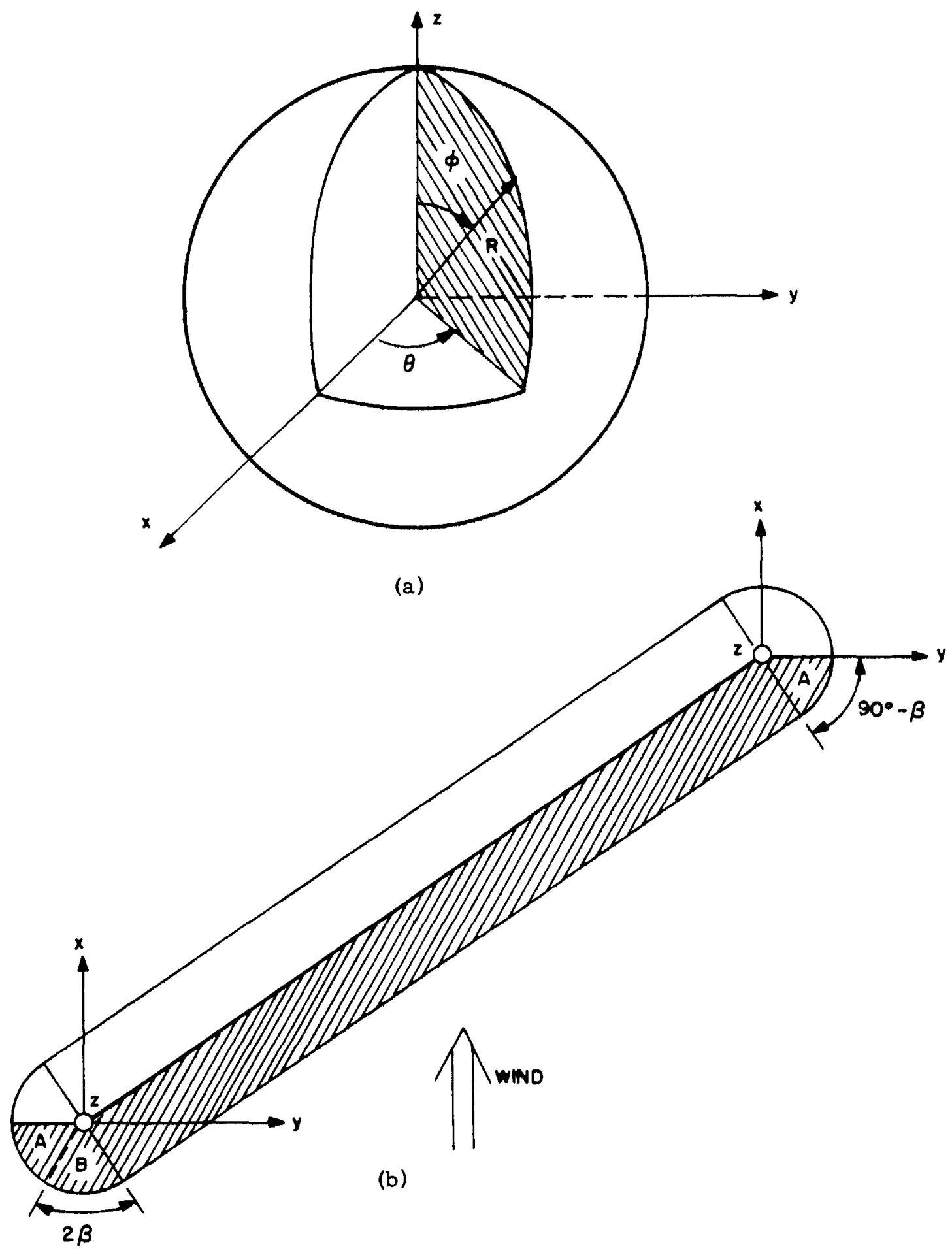

Figure 7. Coordinate System Used to Analyze the Hemispherical End Caps of Configuration 1 
The total force on the caps in the $\mathrm{x}$ direction is the integral of the $\mathrm{x}$ component of the above expression over that portion of the hemispherical surfaces exposed to the flow.

$$
\begin{aligned}
F_{x} & =\iint_{\text {exposed surface }} \mathrm{dF}_{\mathrm{x}} \\
& =-\rho \mathrm{V}^{2} \mathrm{R}^{2}\left[\int_{\pi-\beta}^{3 \pi / 2} \int_{0}^{\pi} \sin ^{3} \phi \cos ^{3} \theta \mathrm{d} \phi \mathrm{d} \theta+\int_{\pi / 2}^{\pi-\beta} \int_{0}^{\pi} \sin ^{3} \phi \cos ^{3} \theta \mathrm{d} \phi \mathrm{d} \theta\right] \\
\mathrm{F}_{\mathrm{x}} & =\frac{4 \rho \mathrm{V}^{2} \mathrm{R}^{2}}{3}\left[\int_{\pi}^{3 \pi / 2} \cos ^{3} \theta \mathrm{d} \theta+\int_{\pi / 2}^{\pi-\beta} \cos ^{3} \theta \mathrm{d} \theta\right] \\
\mathrm{F}_{\mathrm{X}} & =\frac{\rho \mathrm{V}^{2} \mathrm{R}^{2} 16}{9}
\end{aligned}
$$

The limits on the integrals can be determined by inspection of Figure 7. Also by inspection of Figure 7, the total force on the caps in the $y$ direction is zero because of symmetry.

$$
F_{y}=0
$$

The total force on the caps acting normal to the axis of the cylinder is:

$$
\begin{aligned}
& N=F_{x} \cos \beta+F_{y} \sin B \\
\therefore N & =\left(\frac{\rho V^{2} R^{2} 16}{9}\right) \cos \beta
\end{aligned}
$$

and the normal force coefficient of the caps is:

$$
\begin{aligned}
& C_{N}=\frac{N}{(1 / 2) \rho V^{2} R^{2}} \\
& C_{N}=1.16 \cos \beta
\end{aligned}
$$

The pitching moment about the center of the cylinder due to the forces on the end caps is:

$$
M=-F_{y_{A}} L \sin \beta+F_{x_{B}} \frac{L}{2} \cos \beta,
$$

where the Regions $A$ and $B$ are as marked on Figure 7. The above expression becomes obvious upon inspection of Figure 7. The forces in the $y$ direction acting on Region $B$ of the hemispherical end cap are equal and opposite by symmetry, and thus cancel each other. Similarly, the forces in the $x$ direction acting on Regions $A$ of the hemispherical end caps create equal but opposite moments about the center of the cylinder and thus cancel each other. This leaves only the forces in the $\mathrm{y}$ direction acting on Region $\mathrm{A}$ and the forces in the $\mathrm{x}$ direction acting on Region $\mathrm{B}$ to contribute to the pitching moment. 


$$
\begin{aligned}
& F_{x_{B}}=\iint_{\text {Over surface } B} d F_{x} \\
& =-\rho V^{2} R^{2} \int_{\pi-\beta}^{\pi+\beta} \int_{0}^{\pi} \sin ^{3} \phi \cos ^{3} \theta d \phi d \theta \\
& =\frac{-\rho \mathrm{V}^{2} \mathrm{R}^{2} 4}{3} \int_{\pi=\beta}^{\pi+\beta} \cos ^{3} \theta \mathrm{d} \theta \\
& F_{\mathrm{x}_{B}}=\left(\frac{\rho \mathrm{V}^{2} \mathrm{R}^{2} 8}{9}\right) \sin \beta\left(\cos ^{2} \beta+2\right) \\
& F_{y_{A}}=\iint_{\text {over surface } A} d F_{y} \\
& =-\rho V^{2} R^{2} \int_{\pi+\beta}^{3 \pi / 2} \int_{0}^{\pi} \sin ^{3} \phi \cos ^{2} \theta \sin \theta d \phi d \theta \\
& =\frac{-\rho V^{2} R^{2} 4}{3} \int_{\pi+\beta}^{3 \pi / 2} \cos ^{2} \theta \sin \theta d \phi d \theta \\
& \mathrm{F}_{\mathrm{y}_{\mathrm{A}}}=\left(\frac{\rho \mathrm{V}^{2} \mathrm{R}^{2} 4}{9}\right) \cos ^{3} \beta \\
& M=\frac{\rho V^{2} R^{2} 4 L}{9}\left[-\cos ^{3} \beta \sin \beta+\sin \beta\left(\cos ^{3} \beta+2 \cos \beta\right)\right] \\
& M=\left(\frac{\rho V^{2} R^{2} 4 L}{9}\right) 4 \sin 2 \beta
\end{aligned}
$$

and the pitching moment coefficient due to the end caps is:

$$
\begin{aligned}
& C_{M}=\frac{M}{(1 / 2) \rho V^{2} \pi R^{2} D} \\
& C_{M}=0.282 \frac{L}{D} \sin 2 \beta
\end{aligned}
$$

The total force on the caps acting parallel to the axis of the cylinder is:

$$
A=F_{x} \sin \beta+F_{y} \cos \beta
$$


$\mathrm{F}_{\mathrm{x}}$ and $\mathrm{F}_{\mathrm{y}}$ have been determined above. It was found that

$$
\begin{aligned}
F_{x} & =\frac{16 \rho \mathrm{V}^{2} \mathrm{R}^{2}}{9} \\
F_{\mathrm{y}} & =0 \\
\therefore \quad & A=\left(\frac{16 \rho \mathrm{V}^{2} \mathrm{R}^{2}}{9}\right) \sin \beta
\end{aligned}
$$

and the axial force coefficient due to the end caps is

$$
\begin{aligned}
C_{A} & =\frac{A}{(1 / 2) \rho V^{2} R^{2}} \\
C_{A} & =1.16 \sin \beta
\end{aligned}
$$

\section{Analysis of Configuration 1 - The Cylindrical Body}

Figure 8 shows the cylindrical coordinate system used to analyze the body. The unit vector normal to the surface of the body and directed inward is

$$
\mathbf{n}=-\cos \theta \mathbf{i}-\sin \theta \mathbf{i}
$$

The velocity vector of the flow relative to the body is

$$
\mathbf{v}=-\mathrm{v} \sin \alpha \mathbf{i}-\mathrm{v} \cos \alpha \mathbf{k}
$$

Thus the force caused by an infunitesimal stream-tube of air hitting the body and losing its normal component of momentum is

$$
\begin{aligned}
& \mathrm{d} \mathbf{F}=-\rho(\mathbf{V} \cdot \mathbf{n})^{2} \mathrm{~d} \mathbf{S} \\
& \mathrm{d} \mathbf{F}=-\rho R V^{2} \sin ^{2} \alpha \cos ^{2} \theta(\cos \theta \mathbf{i}+\sin \theta \mathbf{i}) \mathrm{d} \theta \mathrm{dz}
\end{aligned}
$$

The total force on the body in the $\mathrm{x}$ direction is the integral of the $\mathrm{x}$ component of the above expression over that portion of the cylindrical surface exposed to the flow.

$$
\begin{aligned}
F_{x} & =\iint_{\text {exposed surface }} \mathrm{dF}_{\mathrm{x}} \\
& =-\rho \mathrm{V}^{2} \mathrm{R} \sin ^{2} \alpha \int_{-\mathrm{L} / 2}^{\mathrm{L} / 2} \int_{\pi / 2}^{-\pi / 2} \cos ^{3} \theta \mathrm{d} \theta \mathrm{dz} \\
\mathrm{F}_{\mathrm{x}} & =\frac{4 \rho R \mathrm{R}^{2} \mathrm{~L} \sin ^{2} \alpha}{3}
\end{aligned}
$$

The limits on the integral can be determined by inspection of Figure 8. Also by inspection of Figure 8 the total force on the body in the y direction is zero because of symmetry.

$$
F_{y}=0
$$




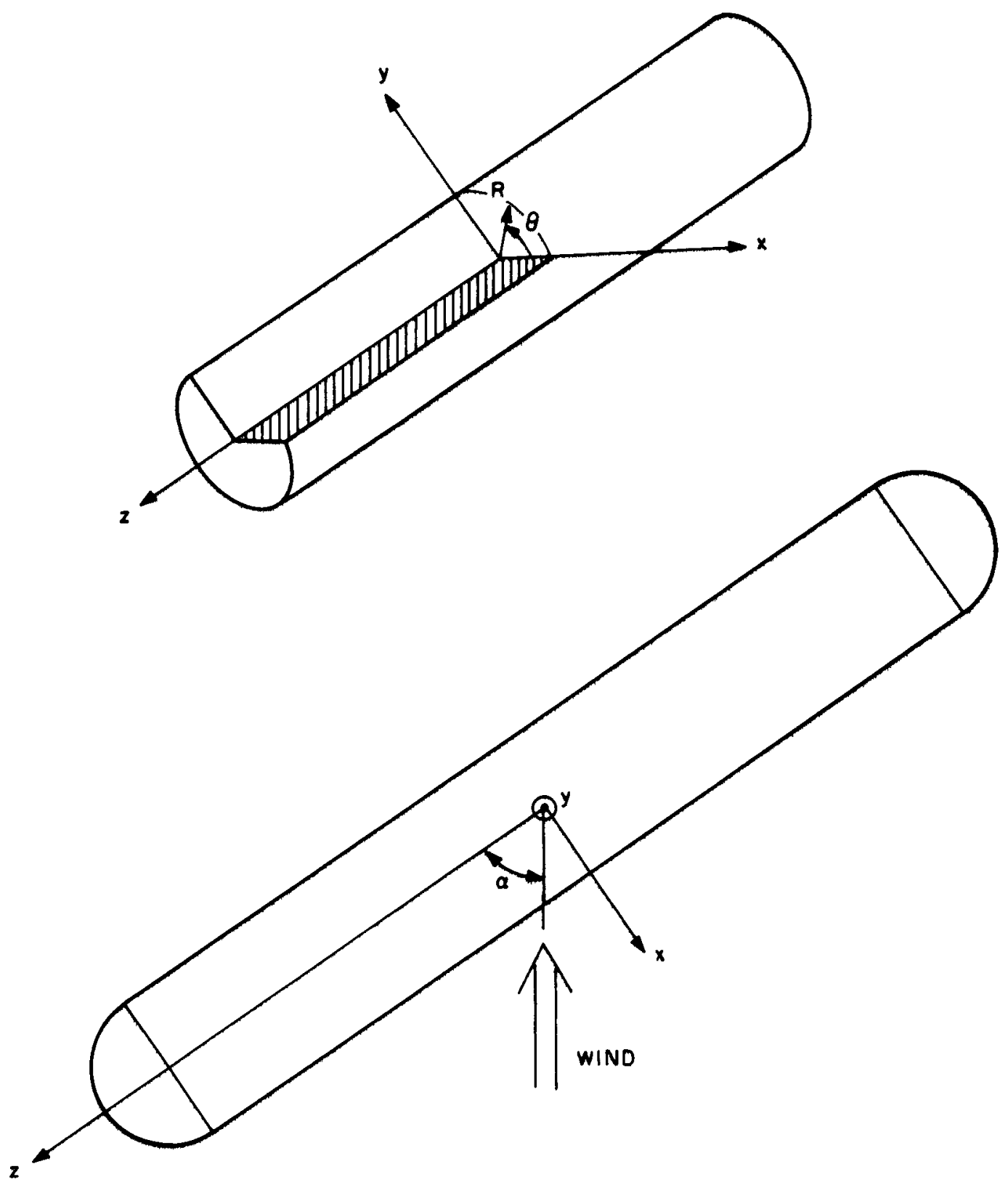

Figure 8. Coordinate System Used to Analyze the Cylindrical Body of Configurations 1 and 2 
The total force on the body acting normal to the axis of the cylinder is

$$
\begin{aligned}
& \mathbf{N}=F_{x} \mathbf{i}+F_{y} \mathbf{i} \\
& \mathbf{N}=\frac{4 \rho R V^{2} L \sin ^{2} \alpha_{1}}{3}
\end{aligned}
$$

and the normal force coefficient of the body is

$$
\begin{aligned}
& C_{N}=\frac{N}{1 / 2 \rho V^{2} R^{2}} \\
& C_{N}=1.70 \frac{L}{D} \sin ^{2} \alpha
\end{aligned}
$$

It is obvious upon inspection of Figure 7 that because of symmetry the forces acting on the cylindrical body of the capsule do not contribute to the pitching moment coefficient or the axial force coefficient.

\section{Analysis of Configuration 1 - Damping in Pitch}

The total damping in pitch coefficient was determined following the analysis of Reference 3 . In this analysis, the effects of the hemispherical end caps were neglected and it was assumed that there is no difference between the pitch angle $\theta$, the pitch rate $\dot{\theta}$, and the corresponding parameters, the angle of attack $\alpha$, and the angle of attack rate $\dot{\alpha}$. In other words, it is assumed that the motion of the center of gravity of the capsule is horizontal and rectilinear. Also, any damping moments due to downwash were neglected. These assumptions imply that the total damping in pitch is approximately due only to the rotational pitching rate of the body about its own axis. Referring to Figure 9 , the tangent of the induced pitch angle due to a steady pitch rate is

$$
\tan \alpha_{1}=\frac{\dot{\alpha} \times \cos \alpha}{V+\alpha \times \sin \alpha}
$$

Assuming that $\alpha_{1}$ is small $(\dot{\alpha} \mathrm{x} \ll \mathrm{V})$, this becomes

$$
\alpha_{1}=\frac{\dot{\alpha} \times \cos \alpha}{V}
$$

It was shown above that for the cylindrical body,

$$
\begin{aligned}
& \mathrm{C}_{\mathrm{N}}=1.70 \frac{\mathrm{L}}{\mathrm{D}} \sin ^{2} \alpha \\
& \frac{\mathrm{dC}_{\mathrm{N}}}{\mathrm{dx}}=\frac{1.70 \sin ^{2} \alpha}{\mathrm{D}}
\end{aligned}
$$

The restoring moment per unit length is then

$$
\begin{aligned}
\frac{\mathrm{dM}}{\mathrm{dx}} & =\frac{-\mathrm{xdN}}{\mathrm{dx}} \\
& =\frac{-\mathrm{xqAdC} n}{\mathrm{dx}} \\
& =-1.70 \frac{\mathrm{Aq}}{\mathrm{D}} \times \sin ^{2} \alpha_{1} \\
& =-1.70 \frac{\mathrm{Aq}}{\mathrm{D}} \times\left[\frac{\alpha \mathrm{x} \cos \alpha}{\mathrm{V}}\right]^{2} \\
\frac{\mathrm{dMI}}{\mathrm{dx}} & =-1.70 \frac{\mathrm{Aq}}{\mathrm{D}}\left[\frac{\alpha \cos \alpha}{\mathrm{V}}\right]^{2} \mathrm{x}^{3}
\end{aligned}
$$




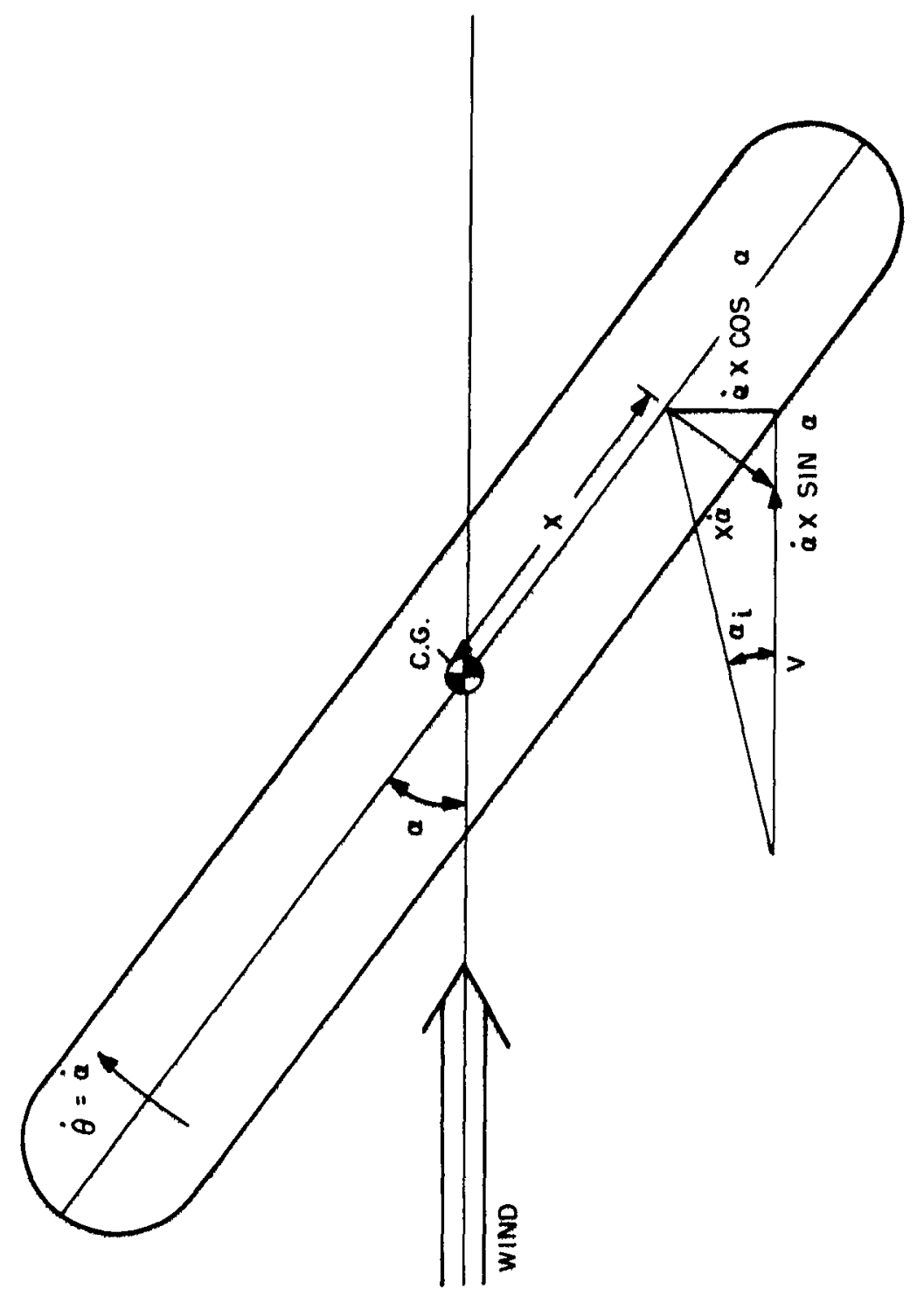

Figure 9. Geometrical Relationships Needed to Determine the Damping in Pitch Coefficient 
Therefore, within the small angle approximation:

$$
\begin{aligned}
& \mathrm{dM}=-1.70 \frac{\mathrm{Aq}}{\mathrm{D}}\left[\frac{\dot{\alpha} \cos \alpha}{\mathrm{V}}\right]^{2} \mathrm{x}^{3} \mathrm{dx} \\
& \mathrm{M}=-3.40 \frac{\mathrm{Aq}}{\mathrm{D}}\left[\frac{\dot{\alpha} \cos \alpha}{\mathrm{V}}\right]^{2} \int_{0}^{\mathrm{L} / 2} \mathrm{x}^{3} \mathrm{dx} \\
& \mathrm{M}=-3.40 \frac{\mathrm{Aq}}{\mathrm{D}}\left[\frac{\alpha \cos \alpha}{\mathrm{V}}\right]^{2} \frac{\mathrm{L}^{4}}{64}
\end{aligned}
$$

so that, by definition:

$$
\mathrm{C}_{\mathrm{M}_{\dot{\alpha}}}=\frac{\mathrm{M}}{\mathrm{qAD}} / \frac{\dot{\alpha} \mathrm{D}}{2 \mathrm{~V}}=0.106 \frac{\mathrm{L}^{4}}{\mathrm{D}^{3}} \frac{\cos ^{2} \alpha}{\mathrm{V}} \dot{\alpha}
$$

Analysis of Configuration 1 - The Total Configuration

The aerodynamic coefficients of the total configuration were determined by adding together those due to the component parts as determined above. Therefore, the total normal force coefficient is:

$$
C_{N}=1.16 \cos \beta+1.70 \frac{\mathrm{L}}{\mathrm{D}} \sin ^{2} \alpha
$$

or since $\beta=90^{\circ}-\alpha$

$$
C_{N}=1.16 \sin \alpha+1.70 \frac{L}{D} \sin ^{2} \alpha
$$

The total pitching moment coefficient is

$$
\begin{aligned}
& C_{M}=0.282 \frac{L}{D} \sin ^{2} \beta \\
& C_{M}=0.282 \frac{L}{D} \sin ^{2} \alpha
\end{aligned}
$$

The total axial force coefficient is

$$
\begin{aligned}
& \mathrm{C}_{\mathrm{A}}=1.16 \sin \beta \\
& \mathrm{C}_{\mathrm{A}}=1.16 \cos \alpha
\end{aligned}
$$

and the total damping in pitch coefficient is

$$
\mathrm{C}_{\mathrm{M}}=0.106 \frac{\mathrm{L}^{4}}{\mathrm{D}^{3}} \frac{\cos ^{2} \alpha}{\mathrm{V}} \dot{\alpha}
$$

Analysis of Configuration 2

Configuration 2 was also analyzed using Newtonian theory, however, since this theory is incapable of predicting pressure forces on concave surface, it was treated as a simple right circular cylinder. In this case the normal force coefficient is that derived above for a cylindrical body, referring to Figure 8.

$$
\mathrm{C}_{\mathrm{N}}=1.70 \frac{\mathrm{L}}{\mathrm{D}} \sin ^{2} \alpha
$$


The unt vector normal to the windward face of the cylinder and directed inward is

$$
\mathbf{n}=-\mathbf{k}
$$

The velocity vector of the flow relative to this face is

$$
\mathbf{v}=-\mathrm{v} \sin \alpha \mathbf{i}-\mathrm{v} \cos \alpha \mathbf{k}
$$

Thus, the force caused by an infinitesimal stream-tube of air hitting the face and losing its normal component of momentum is

$$
\begin{aligned}
& d F=-\rho(V \cdot n)^{2} d s \\
& d F=-\rho V^{2} \cos ^{2} \alpha R \operatorname{drd} \theta k
\end{aligned}
$$

The total axial force on the face is then

$$
\begin{aligned}
& F=-\rho V^{2} R \cos ^{2} \alpha \int_{0}^{R} \int_{0}^{2 \pi} d r d \theta \\
& F=V^{2} \rho R^{2} 2 \pi \cos ^{2} \alpha
\end{aligned}
$$

and the axial force coefficient is

$$
\begin{aligned}
& \mathrm{C}_{\mathrm{A}}=\frac{\mathrm{F}}{(1 / 2) \rho \mathrm{V}^{2} \pi \mathrm{R}^{2}} \\
& \mathrm{C}_{\mathrm{A}}=2 \cos ^{2} \alpha
\end{aligned}
$$

The damping in pitch coefficient for Configuration 2 is the same as that derived above for a cylindrical body.

$$
\mathrm{C}_{\mathrm{M}_{\mathrm{q}}}=0.106 \frac{\mathrm{L}^{4}}{\mathrm{D}^{3} \mathrm{~V}} \cos ^{2} \alpha \dot{\alpha}
$$

For a completely symmetrical right circular cylinder the pitching moment is zero, however, as described above, in two cases Configuration 2 is asymmetrical in that its center of gravity is offset from the geometric center. Therefore, for Case 1

$$
\mathrm{C}_{\mathrm{M}}=0
$$

for Case 2

$$
\begin{aligned}
& C_{M}=\left(\frac{X_{C G}}{D}\right) C_{A} \\
& C_{M}=\frac{0.061}{0.981}\left(2 \cos ^{2} \alpha\right) \\
& C_{M}=0.124 \cos ^{2} \alpha
\end{aligned}
$$


for Case 3

$$
\begin{aligned}
C_{M} & =\left(\frac{X_{C G}}{D}\right) C_{N} \\
C_{M} & =\frac{1.4035}{0.981}(1.70) \frac{L}{D} \sin ^{2} \alpha \\
C_{M} & =2.44 \frac{L}{D} \sin ^{2} \alpha
\end{aligned}
$$

Survey of Available Experimental Data

A literature search was made to determine what has been done in the way of measuring the aerodynamıc coefficients of a right circular cylınder at all angles of attack and at hypersonıc Mach numbers. It was discovered that surprisingly little experimental work has been done on such a fundamental shape. In general, the normal force coefficient and the drag have been measured in supersonic flow at angles of attack of zero or 90 degrees. Very little data exists on static pressure distributions and virtually no dynamic measurements have been made. Most of the experimental work has been done at supersonic Mach numbers and high Reynolds numbers, although some work has been done at low Reynolds numbers. Also, most of the data has been accumulated at angles of attack of zero or 90 degrees, although several papers have investigated the full range of angle of attack. A summary of the experimental data discussed above is given in Figures 10 to 14 and a comprehensive bibliography is given at the end of this report.

\section{Conclusions}

This study yields two results concerning the tumbling motion of Configuration 1

1. At least for the initial tumbling rates given, which are believed to be representative of the actual tumbling rates encountered upon re-entry, the tumbling motion of a cylinder with hemispherical end caps is rather rapidly damped. Even for Case 2 with an initial rate of 115 degrees per second, the tumbling motion is damped in 9 cycles.

2. The stable position of a cylinder with hemispherical end caps is normal to the flow, as can be seen by examining Figures 2,3 , and 4 .

These results support previous theoretical work done on a less comprehensive basis.

In regard to the amount of experimental data avallable for right circular cylinders, this study has disclosed that surprisingly little is known about such a fundamental shape. Dynamic force data and both static and dynamic stability data are especially needed. 


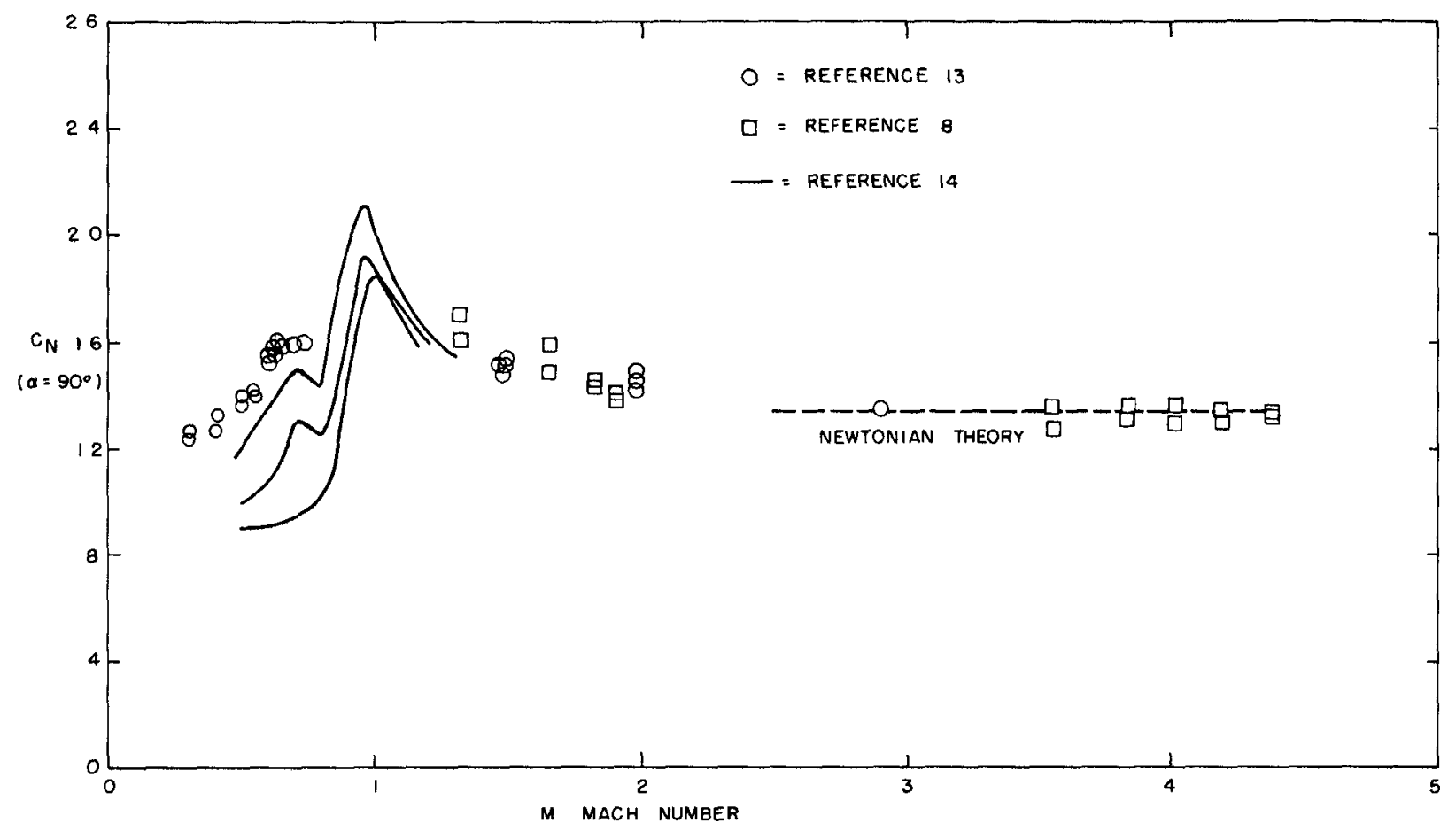

Figure 10. Experimentally Determined Normal Force Coefficient versus Mach Number for Right Circular Cylinders at Angles of Attack of 90 Degrees

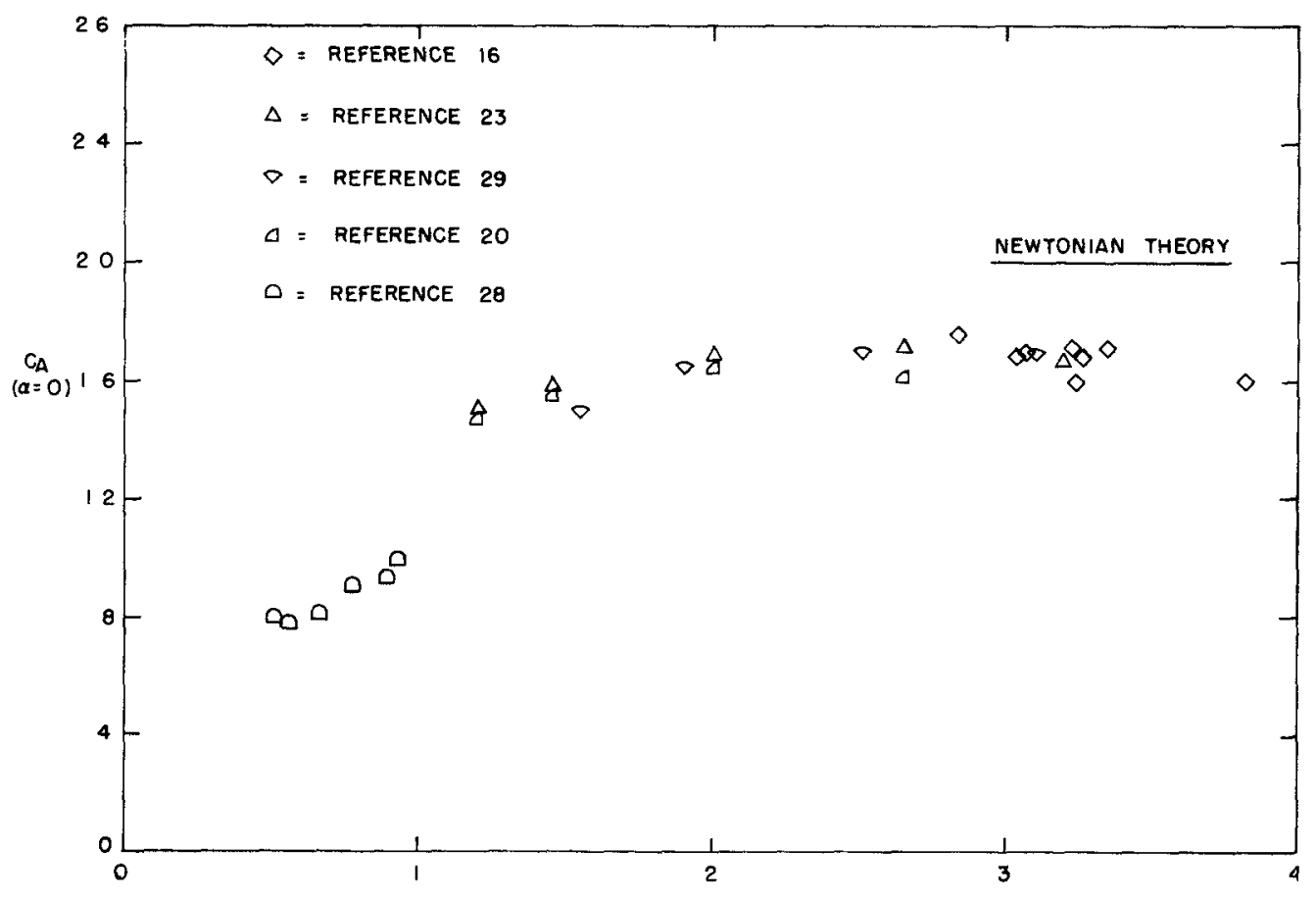

M. MACH NUMBER

Figure 11. Experimentally Determined Axial Force Coefficient versus Mach Number for Right Circular Cylinders at Angles of Attack of 0 Degrees 


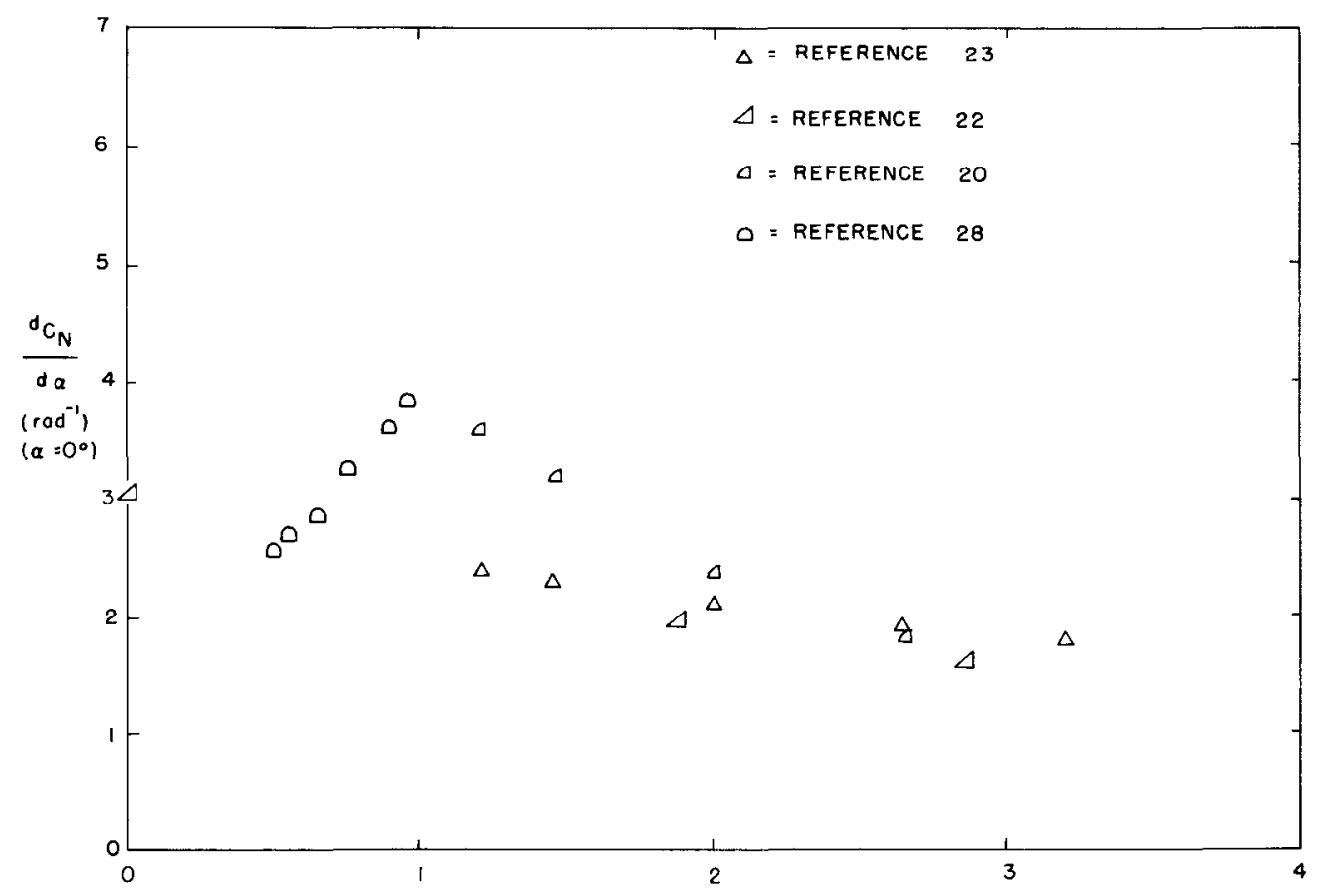

M, MACH NUMBER

Figure 12. Experimentally Determined Normal Force Coefficient Slope versus Mach Number for Right Circular Cylinders at Angles of Attack of 0 Degrees

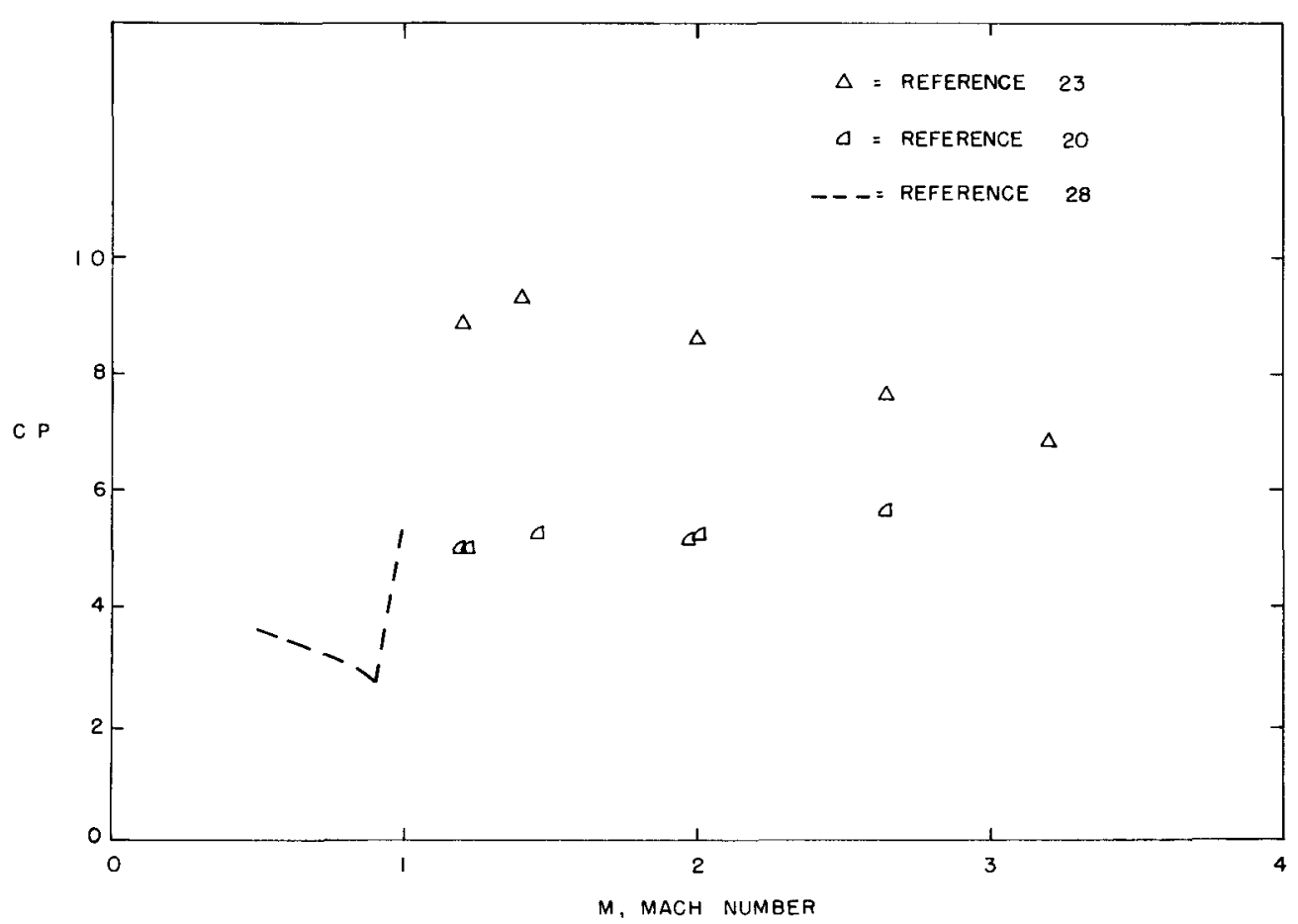

Figure 13. Experimentally Determined Center of Pressure $\left(X_{c p} / L\right)$ Measured from the Base of a Right Circular Cylinder at Zero Angle of Attack versus Mach Number 


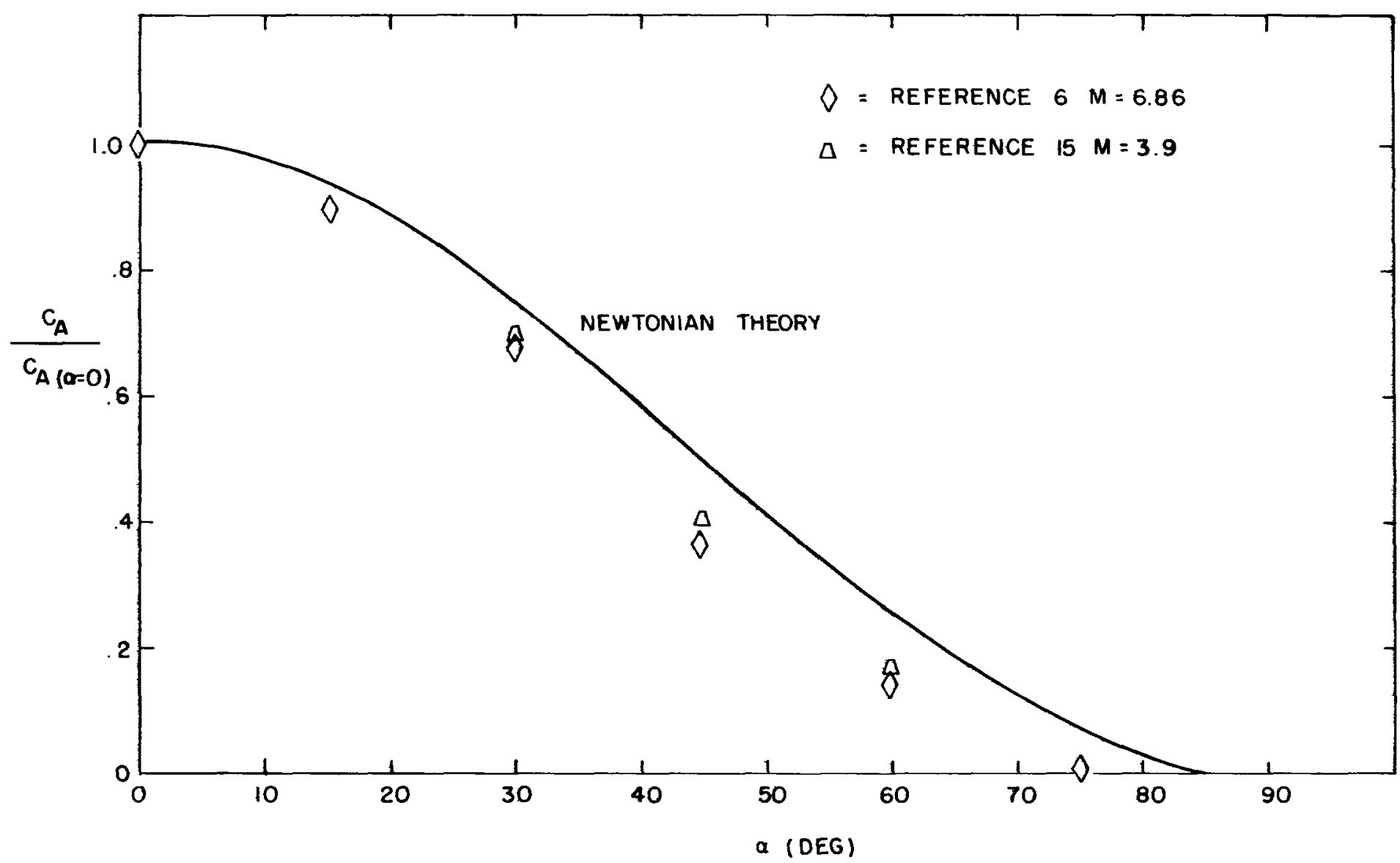

Figure 14. Experimentally Determined Axial Force Coefficient versus Angle of Attack for a Right Circular Cylinder 


\section{LIST OF REFERENCES}

1. Tsien, H. S., "Superaerodynamics, Mechanics of Rarefied Gases, " Journal of the Aeronautical Sciences, Vol. 13, p. 653.

2. Grimminger, G., Williams, E. P., Young, G. B. W., "Lift on Inclined Bodies of Revolution in Hypersonic Flow," Journal of Aeronautical Sciences, Vol. 17, November 1960, p. 675.

3. Raymond and Garber, "On the Stability of a Circular Cylinder at Hypersonic Speeds, "RAND-P-723, January 9, 1956.

4. Kuehn, Donald M., "Experimental and Theoretical Pressures on Blunt Cylinders for Equilibrium and Nonequilibrium Air at Hypersonic Speeds, "NASA-TN-D-1979.

5. Bursnall, William J., and Loftin, Lawrence K. Jr., "Experimental Investigation of the Pressure Distribution About a Yawed Circular Cylinder in the Critical Reynolds Number Range, " NACA-TN2463, September 1951.

6. Penland, Jim A., "Aerodynamic Characteristics of a Circular Cylinder at Mach Number 6.86 and Angles of Attack up to $90^{\circ}, "$ NACA-TN-3861, January 1957.

7. Randall, Duane E., A Method for Estimating the Drag Coefficient of a Tumbling Circular Cylinder, SC-TM-64-528, May 1954.

8. Tewfik, O. K. , and Gredt, A. H., "Heat Transfer Recovery Factor and Pressure Distributions Around a Cylinder Normal to a Supersonic Rarefied Air Stream. Part I, Experimental Data," HE-150-162, January 30, 1959.

9. Tewfik, Omar E1-Khattal, "Heat Transfer, Recovery Factor and Pressure Distributions Around a Circular Cylinder Normal to a Supersonic Rarefied Air Stream. Part II, Comparison of Experiments With Theory, "HE-150-189, May 15, 1959.

10. Tang, Stephen Shien-Pu, "Cylinder Drag in the Hypersonic Free Jets of a Rarefied Air Stream," UC-AS-64-3, January 30, 1964.

11. Masloch, G. J., "Supplementary Cylinder Drag Data for Transition Flow Conditions," AS-63-3, July 1, 1963.

12. Sreekanth, A. K., "Drag Measurements on Circular Cylinders and Spheres in the Transition Regime at a Mach Number of $2, "$ UTIA-74, April 1961.

13. Gowen, Forrest E., and Perkins, Edward W., "Drag of Circular Cylinders for a Wide Range of Reynolds Numbers and Mach Numbers, "NACA-TN-2960, June 1953.

14. Welsh, Clement J., "The Drag of Finite-Length Cylinders Determined from Flight Tests at High Reynolds Numbers for a Mach Number Range from 0.5 to 1. 3, " NACA-TN-2941, June 1953.

15. Goodwin, Glen, Creager, Marcus O., and Winkler, Ernest L., "Investigation of Local Heat Transfer and Pressure Drag Characteristics of a Yawed Circular Cylinder at Supersonic Speeds, "NACA-RMA5SH3 1, January 24, 1956.

16. Long, J. E., "Supersonic Drag Coefficients of Circular Cylinders up to Mach Number 8," AeroBallistic Research Report 353, NAVORD-4382, October 26, 1956.

17. Lindsey, W. F., "Drag of Cylinders of Simple Shapes," NACA-619, 1938. 
13. Horotman, C. C., "The Flow Over a Cylinder with Various Nose Shapes at Zero Angle of Attack at Hypersonic Speeds, "PR-7629-63-14, January 1963.

19. Burbank, Paige B., and Stallings, Robert L., Jr., "Heat-Transfer and Pressure Measurements on a Flat-Face Cylinder at a Mach Number Range of 2. 49 to 4.44," NASA-TM-X-19, August 1959.

20. Strassl, H., "Three Component Measurements of Short Cylinders at Supersonic Speeds, "ZWB/UM3003, November 9, 1948.

21. Davey, Walter T., and Brigsby, Carl E., "Stability Characteristics of Cones and Cylinders at Large Angles of Attack at Mach Number 2. 87," AERON-U-540.

22. Potter, J. Leith., Shapiro, Norman M., and Murphree, William D., "Normal Force Distributions of Right Circular Cylinders in Subsonic and Supersonic Flows," RA-2R4F, December 2, 1954.

23. Walchner, O., "Systematic Wind-Tunnel Measurements on Missiles," NACA-TM-1122, March 1947.

24. Horstman, C. C., "Pressure and Heat-Transfer Measurements Over a Circular Cylinder at Angles of Attack Up to $15^{\circ}$ at $M=11, "$ PR-7629-63-8, May 1963.

25. Gregorek, G. M., and Korhan, K. D., "An Experimental Observation of the Mach Number and Reynolds Number Independence of Cylinders in Hypersonic Flow," AIAA Journal, Vol. 1, No. 1, p. 210.

26. Potter, J. Leith, Myrphree, William D., and Shapiro, Norman M., "Normal Force and Center of Pressure on Right Circular Cylinders," Journal of the Aeronautical Sciences, March $1955, \mathrm{p} .214$.

27. Hall, I. M., "Experiments on Supersonic Flow Over Flat-Nosed Circular Cylinders at Yaw," Philosophical Magazine, Vol. 45, Seven Series 362, March 1954.

28. Naumann, A., "Messungen an einem Zylinder 1-5, Bericht des Aerodymanischen Institutes Aachen," Jahbarch 1943.

29. Erdmann, ZWB Lilienthal Rpt. 139/1 